\title{
A questionnaire-based study to evaluate perception, attitude and opinion of undergraduate medical students on the teaching- learning methodology in pharmacology
}

\author{
Saripilli Preethi Yadav, K. N. V. Anusha* \\ Department of Pharmacology, Rangaraya Medical College, Kakinada, Andhra Pradesh, India
}

Received: 20 January 2020

Revised: 06 March 2020

Accepted: 07 March 2020

*Correspondence:

Dr. K. N. V. Anusha,

Email: knvanusha@gmail.com

Copyright: $(\odot$ the author(s), publisher and licensee Medip Academy. This is an open-access article distributed under the terms of the Creative Commons Attribution Non-Commercial License, which permits unrestricted non-commercial use, distribution, and reproduction in any medium, provided the original work is properly cited.

\begin{abstract}
Background: Pharmacology enables medical students with the art of rational prescriptions of drugs. Reforms in undergraduate teaching are the need of the hour. The purpose of the study was to assess the student's attitude, perception, and feedback on teaching-learning methodology. Students' feedback gives an idea to evaluate teaching methods.

Methods: A cross-sectional study based on questionnaire. A total of 200 second-year medical students studying at Rangaraya medical college, Kakinada, were asked to fill up a pre-validated, predesigned questionnaire containing 17 questions. Descriptive statistics were used for analysis of data, and the results were expressed in percentage (\%).

Results: Out of 200 students, 188 filled the questionnaire, and results were analyzed. 98.43\% wanted case-based learning; $96.34 \%$ wanted more of clinical pharmacology in the curriculum. $83.53 \%$ wanted group discussion. Difficulty level of understanding is CVS (67\%), CNS (65\%), ANS (59\%). 44\% preferred tutorials. Combined use of LCD + Blackboard (86.58) is ideal teaching method. $81.70 \%$ of students studied textbooks only. According to students, pharmacology teachers should make subject interesting (37\%) and student-friendly (31\%). The need for pharmacology orientation during the internship (68.29\%).

Conclusions: The study related to the perception and attitude of the students in learning pharmacology was positive and constructive. The students wish to learn more of clinical and practical oriented way with useful audio-visual aids, and should also be refreshed during internship. Implementation of the same would be helpful for better outcome of students.
\end{abstract}

Keywords: Attitude, Learning, Medical students, Perception, Pharmacology, Teaching

\section{INTRODUCTION}

Pharmacology is a crucial subject for future medical practitioners, which undergoes continuous development and is becoming an essential component of all areas of medicine. To acquire the necessary prescribing skills, medical students must appreciate pharmacological principles and understand their application in clinical situations. ${ }^{1,2}$ As far back as the $19^{\text {th }}$ century researches were conducted regarding students' perceptions toward teaching, learning, and factors that affect undergraduate programs. Studies on students' feedback focused mostly on areas such as learning outcomes, teaching and assessment methodologies, academic staff and educational environment. Students' perceptions comprise effective methods for improvement in teaching basic sciences related to clinical professions, such as pharmacology in health education. Teaching and learning of pharmacology are in a constant stage of reformation, being driven by pressure from the discipline itself, from 
professional bodies, students, as well as due to changes in teaching style. Due to overload content, students often find the subject difficult to remember and recall terms, concepts and drug names. ${ }^{3}$

There is a growing awareness that learners' views of their educational experiences are valuable in assessing the effectiveness of course content and teaching methods. Student feedback is a critical component of the teacherlearner cycle. ${ }^{4}$ Student feedback is considered an invaluable tool for reviewing teaching, evaluation methods, and developing teaching for improving students' performances and provide valuable inputs into the curriculum review processes to help in forming a learner-centered knowledge building process. So, therefore, Student feedback has been considered to be an effective methodology for modification of the undergraduate curriculum and making pharmacology more interesting, and practicable. ${ }^{5}$ Knowledge is to acquire, retain and use the information for skill. Attitude is to react and interpret events. ${ }^{6}$ Understanding current attitude, opinion, and perceptions of future practitioners about pharmacology, both as research and clinical practice, may help to improve teaching on this subject and introduce appropriate changes into the curricula where and when necessary. In recent years undergraduate training in pharmacology has been revolutionized with adoptions of new methods of teaching that focus on supportive learning through novel teaching approaches. ${ }^{7}$

Questionnaires, an objective means of collecting information about people's knowledge, attitudes, and perceptions. $^{3,4}$ A standardized questionnaire was administered to all participants and were asked precisely the same questions, and responses were recorded. ${ }^{3}$

The present study was conducted to determine the attitude, perception, and opinion feedback of teaching/learning Pharmacology using a pre-validated questionnaire among second year M.B.B.S. (third-term) students by Department of Pharmacology at Rangaraya Medical College, Kakinada.

\section{METHODS}

After getting permission obtained from the Institutional Ethics Committee. A total of 200 students were provided with the pre-validated questionnaire. The questionnaire designed in a way that questions are focused on perception, attitude, and opinion on teaching-learning methodology. A pilot study on 15 students was done for questionnaire validation. A questionnaire containing 17 questions based on previous studies and suitably modified for the present set was given (Annexure). Students were asked to mark a single best suitable option in the space provided and were asked not to reveal their identity in the questionnaire. The time allotted for answering the questionnaire was thirty minutes. The completed questionnaires were collected, and the data of 188 students were entered into Microsoft Excel.
The study design was a prospective, cross-sectional, prevalidated, questionnaire-based study was done in the Department of Pharmacology at Rangaraya Medical College and Hospital, Kakinada for a period of 3 days in August, 2018. $2^{\text {nd }}$-year MBBS students were included in the study. Those who were not willing to participate and who did not return the questionnaire within the stipulated time were excluded. Descriptive statistics were used for the analysis of data and were expressed in percentage.

\section{RESULTS}

Out of the 200 students to whom the questionnaire was administered, 188 completed questionnaires were accepted. 12 incomplete questionnaires were discarded. Out of which females were $53.5 \%$ and males were $46.5 \%$. A total of $94 \%$ response rate was observed, as shown in Figure 1.

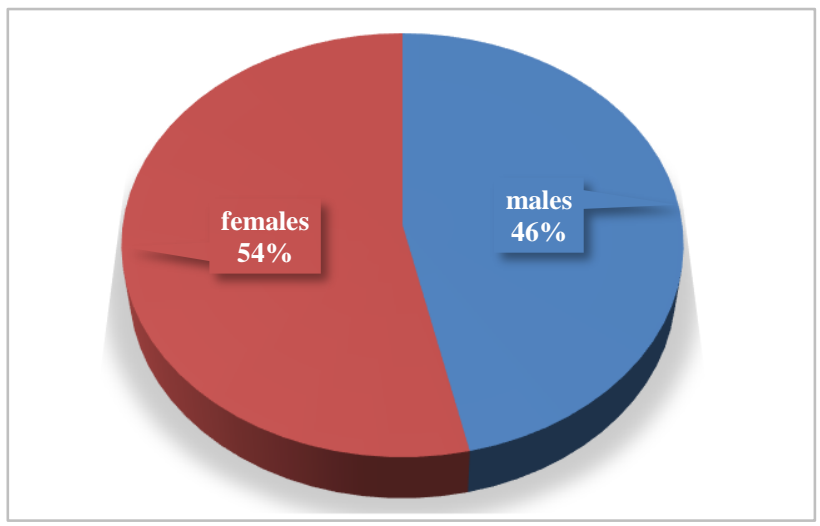

Figure 1: Sex distribution.

Regarding the changes to be done in regular pharmacology teaching, $98.78 \%$ preferred on case-based studies and introduction of more clinical orientation (96.34\%), while $83.53 \%$ preferred on group discussion and $68.90 \%$ preferred on student seminar, we observed about $30 \%$ students think by increasing or decreasing the of the number of lecture make the subject interesting.

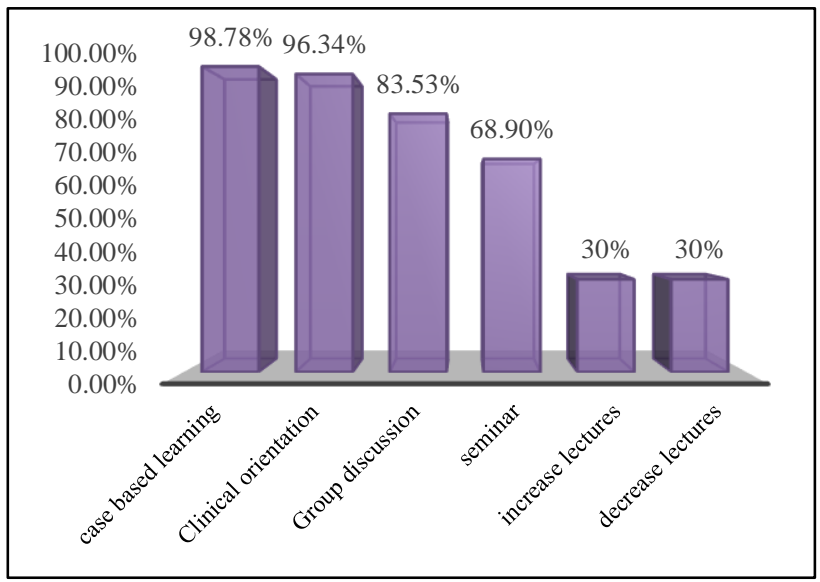

Figure 2: Students' opinion about changes in teachings. 
The preferred method for classroom teaching for a majority of students $86.58 \%$ was the use of a combination of both audio-visual aids and chalk and board, $9.75 \%$ preferred only audio-visual aids and the remaining $9.14 \%$ students preferred only chalk and board method. Around $68.29 \%$ of students mentioned that pharmacology should be taught during the internship, and $31.71 \%$ of students need pharmacology to be taught in and after the 3rd year of the MBBS course.

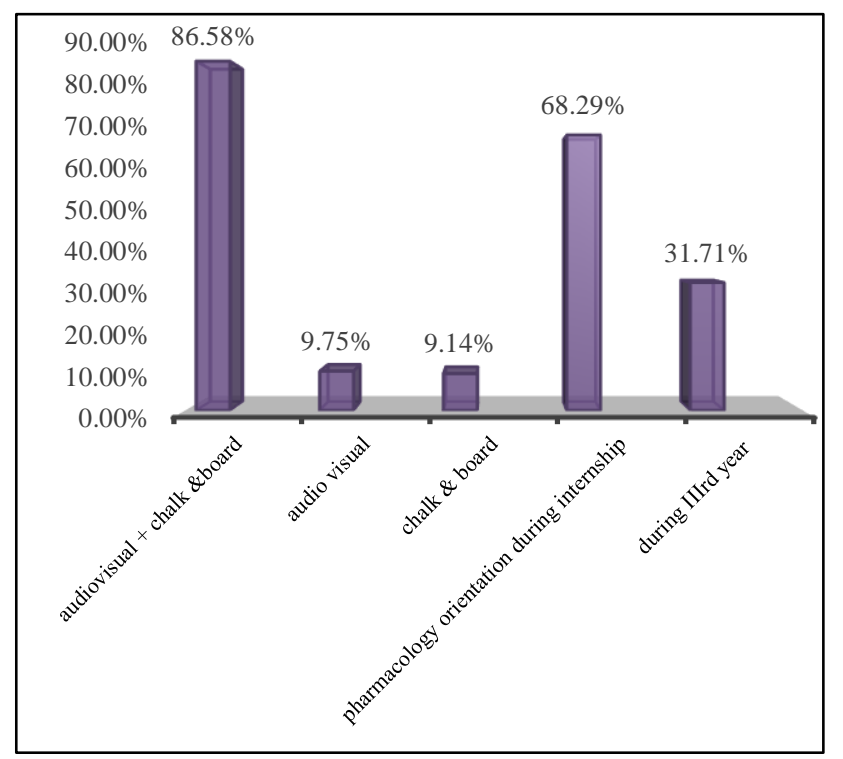

Figure 3: Teaching and learning methods.

The majority of the students found cardiovascular system $(67.07 \%)$, central nervous system $(65.85 \%)$, autonomic nervous system (59.75\%), are difficult to understand compared to chemotherapy $(14.63 \%)$, general pharmacology $(7.92 \%)$, and endocrine system $(6.66 \%)$.

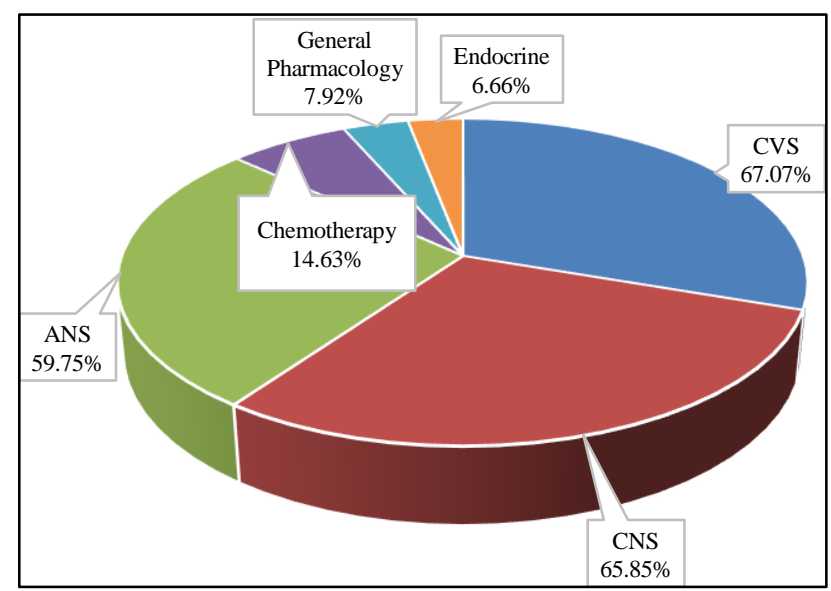

Figure 4: Difficult topics.

$87.09 \%$ of the students came to know about the subject before their entry into 2nd MBBS. As much as $81.70 \%$ of students mentioned that they prefer studying pharmacology by textbooks only, $8.5 \%$ via the internet, $6.09 \%$ by lecture notes, and $3.65 \%$ by university tabs.
When asked about their pattern of studying pharmacology, $39.03 \%$ mentioned that they study regularly because of tests/viva and interactive classes, and $60.97 \%$ of the students' study pharmacology only during tests and exams. $54.87 \%$ students preferred clinicallyoriented lectures as the best method to be added in the regular teaching curriculum, and the second-highest (28.04\%) preference was given to Multiple Choice Question (MCQ)-based study and (14.63\%) was to group discussions classes and $(4.87 \%)$ through seminars. More than $45 \%$ students found that practical's followed by tutorials $(34.20 \%)$ make the subject interesting, and the teaching staff should make the subject interesting (47\%) by incorporating visual -audio clips, or by clinically oriented $(22 \%)$ and also the lectures should be studentfriendly (31\%) to achieve maximal results in grasping students attention to the pharmacology subject. Students agreed that understanding the dosage forms made their clinical postings easy $(64.52 \%)$ to interpret.

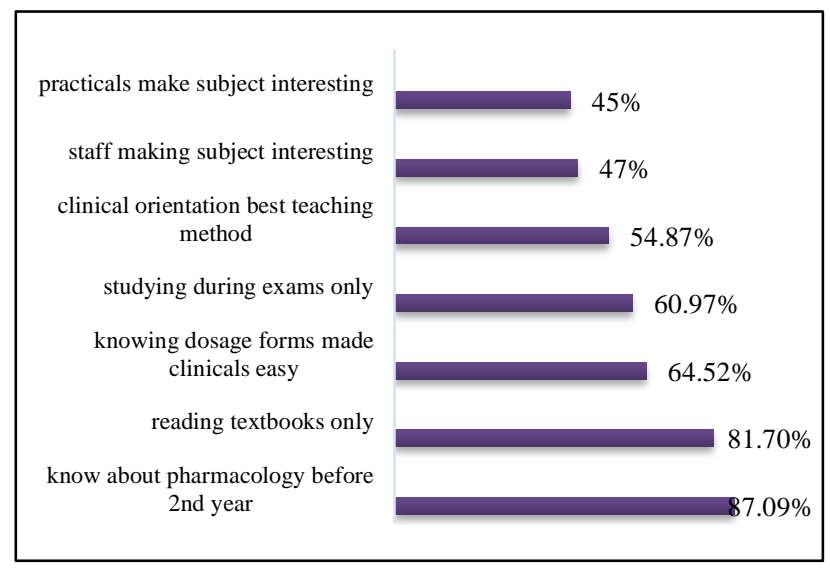

Figure 5: Perceptions of students.

\section{DISCUSSION}

The present study evaluates the perception, attitude, and opinion of second year undergraduate students at Kakinada. Knowledge is to acquire, retain and use the information for skill. Attitude is to react and interpret events. Understanding current attitude, opinion, and perceptions of future practitioners about pharmacology, both as research and clinical practice, may help to improve teaching on this subject and introduce appropriate changes into the curriculum. In the present study, $54 \%$ of females and $46 \%$ were males. $98.78 \%$ opined that case-based learning is the best way of teaching and the staff should make the subject interesting was $47 \%$. $87.09 \%$ know pharmacology before $2^{\text {nd }}$ year and $81.70 \%$ read textbooks for understanding and about $60 \%$ read-only during examination. $86.58 \%$ found that the combination of audio-visual, chalk and blackboard is an effective method of teaching, and $45 \%$ of students mentioned that practicals make the subject interesting. $64.52 \%$ claim that by understanding the dosage forms made their clinical postings easy and $68.29 \%$ thought that orientation to be given during internship. According to 
Bhosale et al, the questionnaire consisted of 25 questions. $45.7 \%$ were females and $54.3 \%$ were males. ${ }^{7}$ About $53.2 \%$ found endocrine difficult to understand and assimilate. 50.8\% thought that case-based learning, 51\% by incorporating MCQ's and $41.7 \%$ of students thought that teaching staff should be student-friendly will make the subject easy to understand. $47.9 \%$ found audio-visual aids are preferred than the traditional chalk and board. $64.9 \%$ found that these sessions helped them during their clinical rotations, so about $56 \%$ thought that they need pharmacology orientation during the internship. More than $50 \%$ learn pharmacology from textbooks. In Balabalajee et al, 59\% knew pharmacology as a subject even before their $2^{\text {nd }}$ year of MBBS. ${ }^{8} 28 \%$ of students found CNS difficult to understand, followed by $20 \%$ of CVS. About $35 \%$ of students opined that tutorials, practicals and staff making subjects interesting to learn. It is found that $37 \%$ of preferred clinical orientation lectures are to be added to the regular pharmacology curriculum. More than $50 \%$ found that audio-visual aids are better teaching-learning methods. Among students, 54\% prefer to read from textbooks only and about $44 \%$ read during exams. 50\% found that learning dosage forms made their clinical posting easy, so $37 \%$ of students thought that orientation during internship might be helpful and needful. In Dutta et al, $44 \%$ of females and $54 \%$ of males' students participated in the study. ${ }^{9}$ Most of the students found ANS, followed by chemotherapy, CVS, CNS is difficult to understand and tutorials help concentrate the subject. $71 \%$ of students thought to introduce group discussion and more lectures into regular pharmacology curriculum and $65 \%$ of students are in favor of case-based learning. $75 \%$ prefer studying from the textbook and $72 \%$ prefer chalk and board much better than audio-visual aid. Students opined that teachers should incline towards clinical orientation. According to Konda et al, the questionnaire comprises of 25 questions. ${ }^{10} 53.8 \%$ know pharmacology before $2^{\text {nd }}$-year MBBS, whereas $39.2 \%$ of students prefer reading from textbooks and about $45 \%$ study only during the examination. $34.2 \%$ mentioned that by including practicals is useful and also make the subject interesting. $35.8 \%$ wanted more lectures and $80.8 \%$ mentioned teaching staff should be student-friendly. $24.2 \%$ opined that pharmacology orientation is useful during an internship, $78.3 \%$ found LCD + blackboard is effective and $20.8 \%$ found CVS atopic is difficult. $54.2 \%$ like to include a seminar in regular pharmacology teaching, and it was found that $74.2 \%$ of students on exposure to dosage forms made their clinical rotation easy.

\section{CONCLUSION}

Teaching and learning are a dynamic process, so the students' feedback provides essential information about the modification in the pharmacology curriculum to make it more exciting and clinically relevant. Formulating new educational strategies is the need of the hour, to mitigate the general stigma that the study of this subject is dry and boring. Curriculum evaluation is the key to the continuous assurance of the quality of education to achieve that students are usually regarded as the best judges to evaluate the effectiveness of teaching content and methods.

\section{ACKNOWLEDGEMENTS}

I sincerely acknowledge my parents Mr. S. Bhaskara Rao and Mrs. Sailaja, and my sister S. Divya Yadav for staying beside me and supporting me all through my study. I thank my guides, Dr. Anusha, MD, Department Of Pharmacology for their guidance and support in the study. I am happy to thank my friends (Ramya, Rupa, Sweta, Kauser, Vamsi) for giving support. I want to thank all postgraduates and clinicians in Rangaraya Medical College who helped me for the study.

Funding: No funding sources

Conflict of interest: None declared

Ethical approval: The study was approved by the Institutional Ethics Committee

\section{REFERENCES}

1. Abdulghani MA, Al-Naggar RA. Students' perceptions about learning pharmacology at a single private institute in Malaysia. J Taibah Univ Med Sci. 2015;10(1):40-4.

2. Prasad SR, Ravi H, Santhosh R. A questionnaire based study on student's opinion on the teaching and learning methods in pharmacology in a medical school in India. Int $\mathrm{J}$ Basic Clin Pharmacol. 2016;5(6):2589-93.

3. Manjunath SM, Nagesh RG, Srinivas TR, Someswara GM. A study on the evaluation of medical students' perception and feedback of teaching-learning of pharmacology in a medical college. Int Arch Integrated Med. 2015;2(9):102.

4. Zaman SU, Beedimani RS, Pavani ANT, Kumar KS. Feedback of second-year medical students' towards teaching/learning of pharmacology in a private medical college of India. Int J Basic Clin Pharmacol. 2016;5:2086-93.

5. Chavda N, Yadav P, Chaudhari M, Kantharia ND. Second year student's feedback on teaching methodology and evaluation methods in Pharmacology. Nat J Physiol Phar Pharmacol. 2011;1(1):23.

6. Kannaiyan V, Shanmugam D, Jaiganesh K. A study on evaluation of knowledge, attitude and practice of pharmacology in second MBBS students. Int J Contemp Med Res. 2016;3(6):1561-4.

7. Bhosale UA, Yegnanarayan R, Yadav GE. Attitude, perception and feedback of second year medical students on teaching-learning methodology and evaluation methods in pharmacology: A questionnaire-based study. Nigerian Med J. 2013;54(1):33.

8. Balabalajee J, Sakthibalan M, Meher BR. A questionnaire based study to assess feedback on 
teaching methodology and evaluation methods in pharmacology. Int $\mathrm{J}$ Basic Clin Pharmacol. 2018;7:2302-8.

9. Dutta S, Devi NK, Das R, Das A, Devi NM. A questionnaire based study to evaluate the perception, attitude and feedback of second year undergraduate students with respect to their pharmacology teaching methodology. Int J Res Med Sci/ 2017;5:3994-6.

10. Konda VR, Prakash GB, Subash KR, Rao KU. Second year medical students' feedback on teachinglearning methodologies and evaluation methods in pharmacology: A questionnaire based study. Int $\mathrm{J}$ Basic Clin Pharmacol. 2017;6:1311-6.

Cite this article as: Yadav SP, Anusha KNV. A questionnaire-based study to evaluate perception, attitude, and opinion of undergraduate medical students on the teaching-learning methodology in pharmacology. Int J Basic Clin Pharmacol 2020;9:599-604. 
ANNEXURE

\section{QUESTIONNAIRES}

1. Students' opinions about changes recommended in teaching pharmacology.

\begin{tabular}{|c|c|c|c|}
\hline S. no. & Opinion about changes recommended & Yes & No \\
\hline 1 & Increase the number of lectures & & \\
\hline 2 & Introduce student Seminars & & \\
\hline 3 & Introduce Case-Based Learning & & \\
\hline 4 & Introduce more Clinical Pharmacology & & \\
\hline 5 & Decrease the number of lectures & & \\
\hline 6 & Introduce Group Discussions & & \\
\hline
\end{tabular}

\section{Teaching-learning methods in pharmacology.}

\begin{tabular}{|l} 
S. no. \\
$\mathbf{7} \quad$ The ideal teaching method for learning Pharmacology is \\
a. Didactic lecture \\
b. Tutorial \\
c. Seminar \\
d. Demonstration \\
The ideal Teaching Learning media for learning Pharmacology is \\
a. LCD projector \\
b. Blackboard \\
c. LCD projector + Blackboard \\
The most difficult system to understand in Pharmacology is \\
a. General Pharmacology \\
b. Autonomic Nervous System \\
c. Central Nervous System \\
c. Cardiovascular System \\
d. Endocrine System \\
e. Chemotherapy
\end{tabular}

3. Perceptions and opinions towards pharmacology teaching and learning by the study subjects.

\begin{tabular}{|c|c|c|c|}
\hline S. no. & & Yes & No \\
\hline 10 & $\begin{array}{l}\text { Did you know about pharmacology before it } \\
\text { was introduced to you in II MBBS? }\end{array}$ & & \\
\hline \multirow{2}{*}{11} & \multirow{2}{*}{$\begin{array}{l}\text { Which of the following type of teaching- } \\
\text { learning methods was most interesting? }\end{array}$} & Lectures & \multirow{2}{*}{ Tutorials } \\
\hline & & Practical & \\
\hline \multirow{2}{*}{12} & \multirow{2}{*}{$\begin{array}{l}\text { Would you like any of the following to be } \\
\text { added as a part of regular teaching in } \\
\text { pharmacology? }\end{array}$} & Seminars & Clinically oriented lectures \\
\hline & & Group discussion & MCQ's \\
\hline \multirow{2}{*}{13} & \multirow{2}{*}{$\begin{array}{l}\text { From where you preferred studying } \\
\text { pharmacology? }\end{array}$} & Lecture notes only & Internet \\
\hline & & Textbooks only & Tabs university provided \\
\hline 14 & $\begin{array}{l}\text { What is your pattern of study in } \\
\text { pharmacology? }\end{array}$ & Regular & Only during exams \\
\hline 15 & $\begin{array}{l}\text { Do you think the pharmacology should be } \\
\text { taught in or after III MBBS? }\end{array}$ & Orientation during internship & Taught in entire III year \\
\hline 16 & $\begin{array}{l}\text { What, according to you, should be the } \\
\text { qualities of a good pharmacology teacher? }\end{array}$ & $\begin{array}{l}\text { Make subject } \\
\text { Interesting }\end{array}$ & $\begin{array}{l}\text { Clinically } \\
\text { oriented }\end{array}$ \\
\hline 17 & $\begin{array}{l}\text { dosage forms in clinical postings \& has } \\
\text { helped me in better understanding of the } \\
\text { subjects }\end{array}$ & Disagree & Agree \\
\hline
\end{tabular}

